\title{
Long Term Follow-up of and Underlying Medical Conditions in Patients with Diabetic Exudative Maculopathy
}

\author{
P. M. DODSON and J. M. GIBSON
}

Birmingham

\begin{abstract}
Summary
Recent reports of risk factors for and survival of patients with diabetic retinopathy do not include exudative maculopathy as a separate entity.

We therefore studied a group of hypertensive Type II diabetic subjects with exudative maculopathy $(n=26)$ compared to a carefully matched hypertensive diabetic comparison group without retinopathy $(n=26)$ over seven years.

Diabetic maculopathy patients had higher mean diastolic blood pressure $(101.6 \pm 14$ versus $94.8 \pm 10 \mathrm{mmHg}, \mathrm{p}<\mathbf{0 . 0 5})$, serum cholesterol $(6.65 \pm 2.2$ versus $5.9 \pm 1.31 \mathrm{mmol} / \mathrm{l}), \quad \mathrm{HDL}_{2}$ subfraction levels $(0.46 \pm 0.23$ versus $0.32 \pm 0.18 \mathrm{mmol} / \mathrm{l})$ and a higher prevalence of hyperlipidaemia (54\% versus $35 \%)$ compared to the comparison group.

After seven years, the maculopathy group showed a strikingly higher prevalence of renal failure and nephrotic syndrome $(42 \%$ versus $8 \%, p<0.05)$ and of macroproteinuria $(58 \%$ versus $15 \%, p<0.01)$ compared to the comparison group. Mortality and cardiovascular disease event rate was $12 \%$ and $38 \%$ in the maculopathy and $15 \%$ and $31 \%$ respectively in the comparison group.

We conclude that although mortality is not significantly higher in diabetics with exudative maculopathy, proteinuria, renal failure and nephrotic syndrome may be associated features on long term follow-up. Hypertension and hypercholesterolaemia may also be risk factors in the development of diabetic maculopathy.
\end{abstract}

The classification of diabetic retinopathy used for many years contains three major groups: background, pre-proliferative and proliferative retinopathy. Diabetic maculopathy, which is usually considered in the background diabetic retinopathy group, is a serious cause of loss of vision in diabetic patients, and is the major cause of blindness in diabetics. ${ }^{1}$

Diabetic maculopathy is not a single pathological entity but can be classified as due to ischaemia (retinal capillary fall-out), or ret- inal oedema due to a breakdown of the blood retinal barrier. Macular oedema can itself be subdivided into focal oedema, which is often characterised by the presence of hard exudate rings, and diffuse oedema which typically is due to diffuse retinal leakage at the posterior pole, with absence of exudates and associated cystoid macular oedema. ${ }^{2}$ Maculopathy occuring in diabetic patients can be difficult to classify, even with fluorescein angiography and may present a mixture of ischaemic and

From: Departments of Diabetes and Ophthalmology, East Birmingham Hospital, Birmingham and Midland Eye Hospital, Birmingham.

Correspondence to: Dr P. M. Dodson, MD, MRCP, Department Diabetes, East Birmingham Hospital, Bordesley Green Hospital, Birmingham B9 5ST. 
oedematous features. We therefore decided to examine a subgroup of diabetic maculopathy patients which had diabetic exudative maculopathy. The advantage of choosing this group is that the exudates are readily visible on fundus examination and fundus photography, so that a fluorescein angiography, a safe but nevertherless invasive procedure, would not be necessary to confirm the diagnosis.

We have compared the maculopathy patients with a carefully matched group without retinopathy.

\section{Patients and Methods}

Patients were recruited following an ophthalmic screening of a diabetic hypertension clinic during 1982. ${ }^{3}$ Twenty-six Type II diabetic patients with exudative maculopathy were identified, and the diagnosis confirmed in the Medical Ophthalmology clinic of the Birmingham and Midland Eye Hospital by ophthalmoscopy, and retinal photography. The definition of maculopathy for the purposes of this study was the presence of exudates within two disc diameters of the fovea. None of these patients had proliferative retinal changes. Twenty-six Type II diabetic patients were also identified who had no evidence of diabetic retinopathy on direct ophthalmoscopy but who were closely matched for age, sex, duration and treatment of diabetes mellitus.

All patients had routine physical examination including blood pressure measurement using a random zero sphygmomanometer. Hypertension was defined according to the WHO criteria ${ }^{4}$ and appropriate cuff correction for obesity made. ${ }^{5}$ Urine was tested with albustix on two differing occasions. Blood samples were taken following an overnight fast (12 hours) for urea and electrolytes, creatinine, fasting lipids and lipoproteins. Hyperlipidaemia was defined as fasting serum cholesterol $>6.5 \mathrm{mmol} / \mathrm{l}$ or triglyceride $>2.1 \mathrm{mmol} / 1 .{ }^{6} \mathrm{High}$ density lipoprotein cholesterol (HDL) was measured following precipitation of very low density lipoprotein (VLDL) by the heparin manganese method. ${ }^{7}$ $\mathrm{HDL}_{2}$ subfraction was assayed by the low molecular weight dextran sulphate precipitation technique. ${ }^{8}$

Following a seven year follow-up, patients were assessed with regard to outcome. Deaths were identified by notes and certificates obtained to ascertain cause of death. Other events including stroke, myocardial infarction, peripheral vascular disease, cardiac failure, development of macroproteinuria (on albustix $\geqslant+$ consistently), renal failure (creatinine $\geqslant 130 \mu \mathrm{mol} / \mathrm{l}$ ) and frank nephrotic syndrome (peripheral oedema, low serum albumin and proteinuria $>1 \mathrm{gm} /$ day) were recorded.

Statistics and analysis were performed on an IBM compatible computerised system using the Oxstat package. Unpaired t-test was used for cross-sectional data and the chisquared test for follow-up data.

\section{Results}

The initial clinical details of the patients studied are shown in Table I. The two groups of hypertensive Type II diabetics were well matched for clinical parameters including type of diabetic treatment and duration of both diabetes and hypertension. However, it was noted that twice as many Type II diabetic hypertensive subjects with maculopathy were on thiazide diuretic therapy for hypertension.

There was a trend towards a higher preva lence of hyperlipidaemia with a higher mean serum cholesterol in the maculopathy group. Hypercholesterolaemia was the predominant form of hyperlipidaemia in both groups (Maculopathy 10 of 14 patients: and comparison group, six of nine patients). In those patients with confirmed hyperlipidaemia thyroid and renal function (creatinine $<120 \mu \mathrm{mol} / \mathrm{l}$ ) were normal. The initial prevalence of proteinuria, current smokers (15\% versus 12\%) and alcohol intake (patients >2 units/day, 19\% versus $15 \%$ ) were similar in the two groups. Mean blood pressure and biochemical values of the two groups are shown in Table II. Diastolic blood pressure was significantly higher in those with maculopathy $(\mathrm{p}<0.05)$. There was a trend to higher mean serum HDL and total cholesterol, with significantly higher subfraction $\mathrm{HDL}_{2}$ values $(\mathrm{p}<0.03)$, but mean triglyceride levels were similar.

During the seven year follow-up period, anti-hypertensive therapy remained unchanged. Three patients in the maculopathy group were treated with bezafibrate for marked hypercholesterolaemia (fasting chol- 
Table I. Initial clinical details of the hypertensive type II diabetic patients with exudative maculopathy ( $n=26)$ compared to diabetic hypertensive patients without retinopathy $(n=26)$

\begin{tabular}{|c|c|c|c|}
\hline & & Maculopathy & Comparison \\
\hline \multicolumn{2}{|l|}{ Number } & 26 & 26 \\
\hline \multicolumn{2}{|c|}{ Mean age (years) } & $56.9 \pm 8.3$ & $57.3 \pm 5.3$ \\
\hline \multicolumn{2}{|c|}{$\begin{array}{l}\text { Body mass index } \\
\left.\text { (weight/height }^{2}\right)\end{array}$} & $30.5 \pm 7.1$ & $28.1 \pm 3.9$ \\
\hline \multicolumn{4}{|c|}{ Duration of (years): } \\
\hline \multicolumn{2}{|c|}{ Diabetes } & $9.8 \pm 9.9$ & $8.9 \pm 6.8$ \\
\hline \multicolumn{2}{|l|}{ Hypertension } & $1.8 \pm 2.2$ & $2.3 \pm 2.5$ \\
\hline \multicolumn{4}{|c|}{ Treatment $(\mathrm{n}):$} \\
\hline \multicolumn{2}{|c|}{ Diabetic: Oral Hypoglycaemic } & 14 & 15 \\
\hline \multicolumn{2}{|c|}{ Insulin } & 10 & 9 \\
\hline \multirow[t]{5}{*}{ Hypertensive: } & Thiazide Diuretics & 10 & 5 \\
\hline & Beta-blockers & 14 & 15 \\
\hline & $\mathrm{Ca}^{2}+$ Antagonist & 9 & 5 \\
\hline & ACE inhibitor & 2 & 1 \\
\hline & Others & 2 & 3 \\
\hline \multirow[t]{2}{*}{ Prevalence: } & Hyperlipidaemia & $54 \% \quad(n=14)$ & $35 \% \quad(n=9)$ \\
\hline & $\begin{array}{l}\text { Proteinuria } \\
(>+ \text { on albustix })\end{array}$ & $11.5 \%(n=3)$ & $7.7 \%(n=2)$ \\
\hline
\end{tabular}

Statistics by unpaired t-test. No statistical differences noted between the two groups. $\mathrm{N}=$ number of patienits.

esterol values initially: $9,8.8$, and $15 \mathrm{mmol} / \mathrm{l}$ ) whereas all other identified hyperlipidaemic subjects in both groups were treated with low fat dietary advice. The results of assessment of patients after seven year follow-up with regard to outcome are shown in Table III. Significantly more patients developed macroalbuminuria, nephrotic syndrome and chronic renal failure in diabetic patients with maculopathy compared to the comparison group. Overall mortality was similar in the two groups, and cardiovascular disease end points were comparable, showing no excess of myocardial infarction in those with maculopathy.

\section{Discussion}

The major findings in this small study suggest that there may be an excess of hyperlipidaemia and poorly controlled hypertension associated with maculopathy in Type II diabetic hypertensive subjects. The major development on long follow-up of maculopathy appears to be the renal complications of diabetes, whereas cardiovascular disease

Table II. Initial blood pressure and biochemical results in the patients with exudative maculopathy compared to the comparison group

\begin{tabular}{|c|c|c|}
\hline Mean values & $\begin{array}{c}\text { Patients with } \\
\text { Maculopathy }(n=26)\end{array}$ & $\begin{array}{c}\text { Comparison } \\
\text { group }(n=26)\end{array}$ \\
\hline \multicolumn{3}{|c|}{ Blood pressure (mmHg) } \\
\hline Systolic & $185.6 \pm 20.7$ & $181.8 \pm 19.3$ \\
\hline Diastolic & $101.6 \pm 14^{*}$ & $94.8 \pm 10.0$ \\
\hline $\begin{array}{l}\text { Blood glucose } \\
\text { (mmol/l) }\end{array}$ & $10.1 \pm 2.01$ & $10.1 \pm 3.6$ \\
\hline Glycosylated $^{S}$ & $11.9 \pm 2.05$ & $10.9 \pm 2.8$ \\
\hline \multicolumn{3}{|l|}{ Haemoglobin (\%) } \\
\hline Creatinine $(\mu \mathrm{mol} / \mathrm{l})$ & $90.5 \pm 14.8$ & $89.7 \pm 14.1$ \\
\hline \multicolumn{3}{|c|}{ Fasting serum (mmol/l) } \\
\hline Cholesterol & $6.65 \pm 2.2$ & $5.9 \pm 1.3$ \\
\hline Triglyceride & $1.73 \pm 1.5$ & $1.6 \pm 0.7$ \\
\hline HDL-cholesterol & $1.49 \pm 0.4$ & $1.31 \pm 0.31$ \\
\hline$H D L_{2}$ & $0.46 \pm 0.2+$ & $0.32 \pm 0.18$ \\
\hline LDL-cholesterol & $2.88 \pm 1.6$ & $2.95 \pm 0.98$ \\
\hline
\end{tabular}

${ }^{*} p<0.05+p<0.03$ by unpaired $t$-test.

${ }^{T}=$ grand mean of all glucose values recorded in clinic preceding 1982 (range of number of values 8-39).

$s^{s}=$ grand mean of all $\mathrm{Hb} A_{1}$ values preceding 1982 (range of number of values 2-5). 
Table III. Outcome in patients with maculopathy and comparison group after seven year follow-up

\begin{tabular}{|c|c|c|}
\hline & $\begin{array}{l}\text { Maculopathy } \\
\quad(n=26)\end{array}$ & $\begin{array}{c}\text { Comparison } \\
(n=26)\end{array}$ \\
\hline \multicolumn{3}{|l|}{ Mortality } \\
\hline Total & $12 \% \quad(3)$ & $15 \%(4)$ \\
\hline Neoplastic disease & $4 \% \quad(1)$ & $4 \%(1)$ \\
\hline \multicolumn{3}{|l|}{ Cardiovascular disease } \\
\hline Stroke & $12 \% \quad(3)$ & $4 \%(1)$ \\
\hline Myocardial infarction & $12 \% \quad(3)$ & $12 \%(3)$ \\
\hline Periphral vascular disease & $8 \% \quad(2)$ & $4 \%(1)$ \\
\hline Cardiac failure & $8 \% \quad(2)$ & $12 \%(3)$ \\
\hline Total & $38.5 \%(10)$ & $31 \%(8)$ \\
\hline \multicolumn{3}{|l|}{ Renal disease } \\
\hline Proteinuria & & \\
\hline ( $3+$ on albustix) & $58 \%(\mathrm{n}=15)+$ & $15 \%(n=4)$ \\
\hline Nephrotic syndrome & & \\
\hline Chronic renal failure & $42 \%(\mathrm{n}=11)^{*}$ & $8 \%(n=2)$ \\
\hline
\end{tabular}

$+\mathrm{p}<0.01$ and ${ }^{*} \mathrm{p}<0.05$ by chi-squared test.

events show no major difference from those hypertensive Type II diabetics without maculopathy. The association of increased thiazide diuretic usage in patients with maculopathy is interesting owing to the adverse effects on blood glucose control and lipid levels that these agents are known to have. ${ }^{9}$

It appears from other studies of the microcirculation of the retina, ${ }^{10}$ that hyperlipidaemia predisposes to venous and arteriolar occlusion, whereas HDL-cholesterol levels are not related. This study supports this finding with increased rather than lower values of $\mathrm{HDL}$ and $\mathrm{HDL}_{2}$ subfraction cholesterol values in diabetic exudative maculopathy patients.

This study has limitations and caution must be exercised in over-interpretation. The initial study groups were small in number and the follow-up of these patients was performed in routine hospital diabetic clinic, allowing variations in exact management. These factors may minimise major initial differences between the groups and variation in individual patient management may have an influence on outcome. The exact degree of control of hypertension, hyperlipidaemia and diabetes related to outcome is not addressed by this study owing to paucity of standardised data.

However this report does suggest that hyperlipidaemia and control of hypertension might be related to the development of dia- betic maculopathy. Hypertension is well described as a risk factor for-development of macro- and microvascular complications of diabetes. $^{11,12}$ One recent report has highlighted the adverse association of increased mortality and the ocular complications of diabetes. ${ }^{13}$ These include moderate to severe non-proliferative and proliferative retinopathy, cataract, and glaucoma (both neovascular and other causes) in both Type I and Type II diabetic patients. No data is included specifically with regard to exudative maculopathy. ${ }^{13}$ Further suggestive support for a link between hyperlipidaemia and exudative maculopathy is added by the reduction of exudates associated with clofibrate therapy, ${ }^{14}$ and one previous report linking retinal exudation and hypercholesterolaemia. ${ }^{15}$

Further studies are needed to address these issues. As maculopathy is still the major cause of blindness in diabetic subjects, it is all the more urgent to identify the risk factors for this disorder, which might lead to benefit from medical treatment as well as laser therapy. Indeed this hypothesis is being explored with regard to the effect of lipid lowering therapy in relation to the development of microalbuminuria in diabetic subjects. Animal experiments have suggested there may be benefit using the HMG CoA reductase inhibitor drugs to lower LDL-cholesterol levels. ${ }^{16}$

We conclude from this small study that hypertension and hyperlipidaemia may be associated in a diabetic patient with the 
development of exudative maculopathy. Follow-up data suggests an association of exudative maculopathy with the renal complications of diabetes.

\section{References}

${ }^{1}$ Ghafour I, Allan D, Foulds WS: Common causes of blindness and visual handicap in the West of Scotland. Br J Ophthalmol 1983, 67: 209-13.

${ }^{2}$ Bresnick GH: Diabetic maculopathy: A critical review highlighting diffuse macular oedema. Ophthalmology 1983; 90: 1301-17.

${ }^{3}$ Pacy PJ, Dodson PM, Beevers M, Fletcher RF, Taylor KG: Prevalence of hypertension in White, Black, and Asian diabetics in a district hospital diabetic clinic. Diabetic Medicine 1985, 1: 125-30.

${ }^{4}$ World Health Organisation. Report of the WHO Expert Committee on Hypertension. WHO Technical Report Services, Number 6461987.

${ }^{5}$ Maxwell MM, Waks AV, Schroth PC, Karam C, Dornfeld LP: Error in blood pressure measurement due to incorrect cuff size in obese patients. Lancet 1982, ii: 33-35.

${ }^{6}$ The British Hyperlipidaemia Association: Detection and management of blood lipid disorders. Current Science 1990.

${ }^{7}$ Burstein M, Scholmick HR, Morfin R: Rapid method for isolation of lipoproteins from human serum by precipitation with polyanions. $J$ Lipid Res 1970, ii: 583-95.

${ }^{8}$ Ferns GA, Galton D, Landon J, Williams PJ: Measurement of high density lipoprotein subfraction $2\left(\mathrm{HDL}_{2}\right)$ by a simple precipitation method. Clin Sci 1981; 62: 16-17.
${ }^{9}$ Pacy PJ, Dodson PM, Kubicki AJ, Fletcher RF, Taylor KG: Comparison of the hypotensive and metabolic effects of bendrofluazide therapy and a high fibre, low fat and low sodium diet in diabetic subjects with mild hypertension. J Hypertens 1984, 2: 215-20.

${ }^{10}$ Dodson PM, Galton DJ, Hamilton AM, Blach RK: Retinal vein occlusion and the prevalence of lipoprotein abnormalities. Br J Ophthalmol 1982, 66: $161-64$

${ }^{11}$ Klein R, Klein BE, Moss SE, Davis MD, DeMets DL: The Wisconsin Epidemiologic Study of Diabetic Retinopathy. Arch Ophthalmol 1984, 102: 527-32.

${ }^{12}$ Reckless JPD, Betteridge DJ, Wu P, Payne B, Calton DJ: High density and low density lipoproteins and prevalence of vascular disease in diabetes mellitus. $\mathrm{Br}$ Med J 1978; i: 883-6.

${ }^{13}$ Garcia MJ, McNamara PM, Gordon T, Kannel WB: Morbidity and mortality in diabetics in the Framingham population: Sixteen year follow-up. Diabetes 1974, 23: 105-11.

${ }^{14}$ Harrold BP, Marmion VJ, Gough KRG: A double blind controlled study of clofibrate in the treatment of diabetic retinopathy. Diabetes 1969 , 18: 285-91.

${ }^{15}$ Esmann V, Kundbaek K, Madsen PH: Types of exudates in diabetic retinopathy. Acta Med Scand 1963, 174: 375-80.

${ }^{16}$ Kasiske BL, O’Donnell MP, Garvis WJ, et al : Pharmacologic treatment of hyperlipidemia reduces glomerular injury in rat $5 / 6$ nephrectomy model of chronic renal failure. Cir Res 1988, 62: 367-74. 